\title{
Dynamic Performance of the Freight Vehicle with Orientation Resistance Controller
}

\author{
Hechao Zhou ${ }^{1, a}$, Jimin Zhang ${ }^{2, b}$, Shuyi Zhang ${ }^{3, c}$, Haixuan Geng ${ }^{4, d}$ \\ ${ }^{1}$ Institute of Rail Transit,Tongji University,Shanghai,201804, China \\ ${ }^{2}$ Institute of Rail Transit,Tongji University,Shanghai,201804, China \\ ${ }^{3}$ Institute of Rail Transit,Tongji University,Shanghai,201804, China \\ ${ }^{4}$ Institute of Rail Transit,Tongji University, Shanghai,201804, China \\ aemail:zhouhechao@tongji.edu.cn, bemail:zjm397a@163.com, \\ cemail:1532679@tongji.edu.cn, ${ }^{\mathrm{d}}$ email: 360291841@qq.com
}

Keywords: Railway freight vehicle; Mid-cross rod; Single orientation resistance controller; Dynamic performance

\begin{abstract}
The dynamic performance of the empty case is worse than the loaded case to the railway freight vehicle in general. The gap damping idea is referred to be used to improve the ride index of the three piece mid-cross bogie vehicle when the friction damper force is downed in this paper. It covers stable security and vibration performance of the model and its parameters of the vehicle with gap resistance controller. There has an apparent difference between the empty case and the loaded case. Especially the vertical performance of the empty case will become worse with the relative friction coefficient largely decreased. The worse performance results from that the vibration energy will increase, and the relative friction coefficient will be lowed down in some degree and the resistance is not to damp the vibration when the speed is increasing to a certain value.
\end{abstract}

\section{Introduction}

In general, the dynamic performance, such as hunting speed, derailment coefficient, unloaded coefficient and the ride index, vibration acceleration, of the empty case is worse than the loaded to the railway freight vehicle. So how to balance the performance between the empty and loaded becomes the concerned problem to the experts in the field. The freight vehicle equipped with the bogies, which are three-piece bogies with the mid-cross rod, is investigated with the high relative friction coefficient to improve the dynamic performance of the empty case. However, the vibration acceleration amplitude of the empty case will become high with the high relative friction coefficient. The empty case performance is better than the vehicle with loaded when the relative friction coefficient is high and the running velocity is low. With the velocity increasing, the empty performance will low down and become worse than the loaded case. Especially the vertical performance of the empty vehicle will become worse with the relative friction coefficient largely decreased. The trend of the dynamic performance is same as the normal three-piece bogie vehicle when it is equipped with the cross rod. The reason is that the relative friction coefficient is kept in the design condition and the friction damper can provide the basis damping resistance when the velocity is relatively low and the vibration frequency is low, and the worse performance results from that the vibration energy will increase, and the relative friction coefficient will be lowed down in some degree and the resistance is not enough to damp the vibration when the velocity is increasing to a certain value. The relative friction coefficient and the damp resistance will be more decreased with the vehicle running time because of the wear away and the performance of the empty will become worse. The passive damp control idea is inferred to increase the resistance when the relative friction coefficient is lowed down. The empty case performance will be improved with the passive resistance controller equipped because the damping resistance can't be decreased as the relative friction coefficient lowed down in the condition. The feature can be achieved by the resistance controller design and the bogies' structure design.

The paper treats that a single direction resistance controller which resistance coefficient can be 
changed is equipped to the mid-cross pieces bogie from the above idea. The dynamic model is set up and the dynamics performance is simulated and analyzed.

\section{Freight vehicle with gap resistance controller Modeling}

The hypothesis, which is given in reference $[1,5,6]$, such as the every component as the rigid body, only one vehicle considered and the rail elastic neglected, etc., will be kept. And some new simplicities are given according the vehicle with the direction resistance controller: The resistance controllers are equipped in the center suspension system of the three-piece mid-cross bogie, one resistance controller every side. The resistance controller force is simplified to the center of the center suspension system when the dynamics performance is simulated. Hence, the resistance controller force only takes into effect to the bounce, and there isn't affection to other degree movement of the bolster. The fig. 1 shows that the forces of the bolster (front bolster as an example) which are from the body and the frames.

The symbols of fig. 1 are: $\mathrm{C}$ represents the body, $\mathrm{S}$ represents frame,L is left and $\mathrm{R}$ is right, $\mathrm{C}$ denotes the center plate and s denotes the elastic side bearing, $F_{S B L(R) z C S}(z, \dot{z})$ (Cs represents the viscous resistance controller coefficient)is the damper force from the alterable force resistance controller, $F_{C B L(R) z}$ is the force at the elastic side bearing from the body, $F_{C B z}$ is the force at the center plate from the body, $M_{C B c z}$ and $M_{C B s z}$ are the friction moments at the center plate and the elastic side bearing separately. The definition of other forces and torques can get from the reference [5,6]

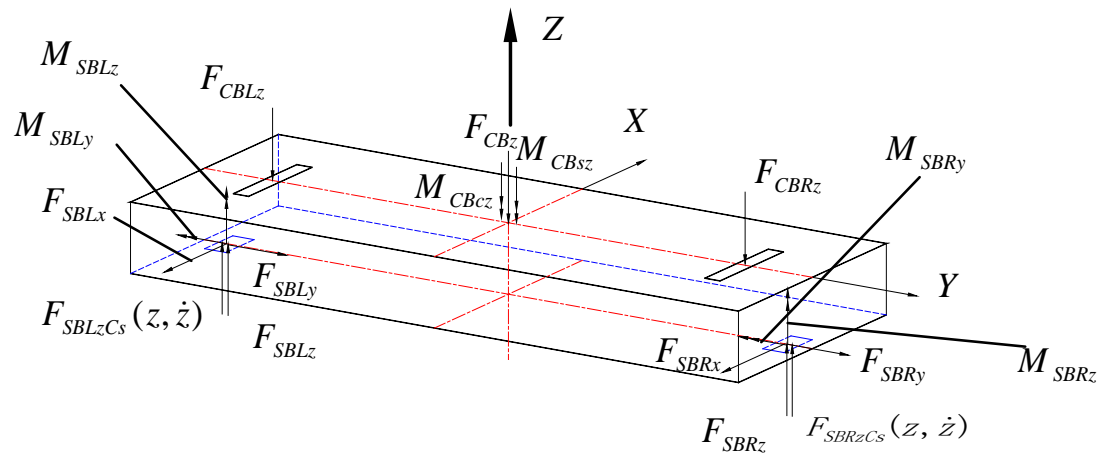

Fig.1 force and torque at bolster from the body and frames

The bounce equation of the bolster is following:

$$
M \ddot{Z}-F_{C B L Z}-F_{C B Z}-F_{C B R z}+F_{S B L Z}+F_{S B R z}+F_{S B L Z C S}(z, \dot{Z})+F_{S B R Z C S}(z, \dot{z})=0
$$

When the two lasted factors of the left in equation(1) are taken off, the bounce equation is as same as the normal three-piece elastic side bearing bogie. The other equations of the bolster is as same as the normal contact elastic side bearing bolster's and won't be given here because the alterable resistance controller takes into effect to the bounce movement.

Because the structure of the front bogie and the rear bogie is same and the car bogy is taken as a symmetry rigid body, the dynamic performance model can be given by half vehicle in fig.2. In fig.2, Cs represents the resistance controller coefficient of the simple direction alterable resistance controller. 


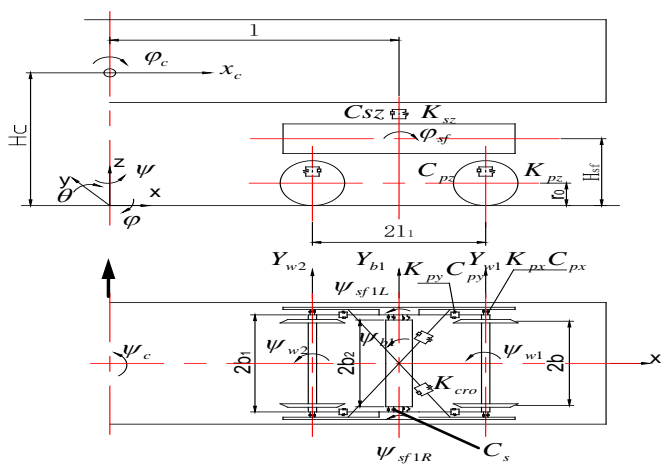

Fig.2 simulating model of the mid-cross rod three pieces bogie vehicle

$F_{S B L(R) Z C S}(z, \dot{Z})$ is the resistance controller force from the alterable resistance controller in equation (1),satisfies:

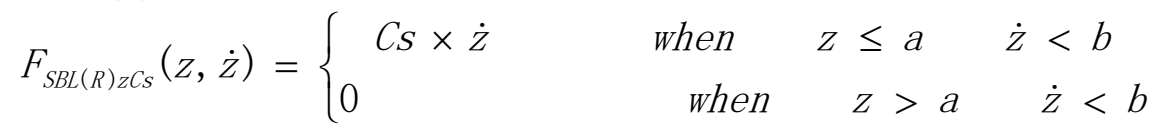

In equation (2), a and $b$ are constant and are defined according to the model and the model requirement, and it shows that the resistance controller takes into effect when the bolster moves down in vertical in the condition that the vertical vibration displacement is less than a and the vibration velocity is less than $b$, in other word, the resistance controller take its effect only in single direction. The resistance controller can be designed to take into effect when the vibration is larger than a, as following:

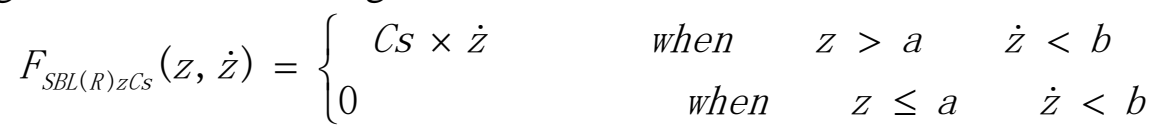

The equation (2) is adopted to simulate the single direction resistance controller and the whole vehicle dynamic performance in this paper and $\mathrm{b}$ is 0 , which the bolster moves down along $\mathrm{z}$ axle.

\section{Digital simulation and results}

In simulating, the mainly parameters follow: The empty body mass is 16 tons and body filled with freight is 75 tons; the springs of the center suspension are two-class stiffness which the first stiffness is $2.6 \mathrm{MN} / \mathrm{m}$ and the second is $4.4 \mathrm{MN} / \mathrm{m}$ (side of the bogie); the load style between body and bolster is the center plate and the usual contact elastic side bearing. The other parameters can be seen in attachment 1 .

\section{Hunting speed calculating}

The vehicle system is nonlinear, also the hunting moving differential equation is. In this paper, the limit circle method is applied to estimate the hunting moving critical velocity $\left(V_{c r}\right)$ of the vehicle stability.

The hunting movement of the vehicle is simulated with a multi DOFs system. The Matrix of the differential equations is:

$$
[M] \ddot{X}+C(x, \dot{x})+K(x, \dot{x})=0
$$

where: M, Mass Matrix; C, Resistance Matrix; K, Rigidness Matrix and x, State Vector.

The four class Runge-Kutta numerical integrator is applied to solve the equation (4). Then the critical velocity is determined by the limit circle. The principle of the way is that the limit circle of the every body's vibration is convergence or radiation or not when the disturbance is applied to the vehicle. If every vibration is convergent, the vehicle is stability; otherwise, the vehicle is instability. And if the limit circle is not convergence and radiation, the vehicle is in a critical state, this running speed becomes the critical velocity $\left(V_{c r}\right)$. In the new wheel and the new rail, the mid-cross three piece bogie vehicles's $V_{c r}$ varying with the friction coefficient $\mu$ of the wedges is listed in 
table 1. From table 1, we know that the gap resistance controller has very small affection to the hunting speed in empty and loaded case.

Table 1 the hunting critical speed of the empty vehicle

\begin{tabular}{|l|c|c|c|c|}
\hline & \multicolumn{2}{|c|}{$\begin{array}{c}\text { without gap resistance } \\
\text { controller(km/h) }\end{array}$} & \multicolumn{2}{c|}{$\begin{array}{c}\text { with gap resistance } \\
\text { controller(km/h) }\end{array}$} \\
\hline case & empty & loaded & empty & loaded \\
\hline$\mu=0.1$ & 121 & 174 & 121 & 176 \\
\hline$\mu=0.2$ & 135 & 222 & 136 & 220 \\
\hline$\mu=0.3$ & 141 & 208 & 208 & 208 \\
\hline
\end{tabular}

\section{Vibration and ride index calculating}

From mechanics, the reason of the high vertical ride index of the empty case is that the vertical resistance force isn't enough. It is to gain the enough resistance force in the vertical when the velocity is relatively high and the relatively coefficient of the friction wedge is low that the single direction alterable resistance controller is equipped to the vehicle with the mid-cross three-piece bogie. The ride index of the empty case is mainly calculated in the straight track in the paper. To loaded case, the ride index can be calculated in the straight track also, but only the conclusion of the affection equipped with the resistance force controller is given. The dynamics performance of fig. 2 model is simulated and the following work cases are studied: first, there is only the friction wedge and the relative coefficient is varying; second, the single resistance controller is equipped, and the dynamics performance affects with the resistance coefficient varying and the constant a varying.

The running stability of the vehicle is shown with the ride index and the max acceleration. The performance simulation calculates the vehicle with the three-piece bogie equipped with the mid-cross at 80,100,120,130 and $140 \mathrm{~km} / \mathrm{h}$ and the rail disturbance is correspond with American 5 class rail spectrum with and without the single direction resistance controller (The resistance factor is $C s N \cdot \mathrm{s} / \mathrm{m}$ ). The law that the resistance factor is determined is: When the relative friction coefficient $\varphi$ is 0.049 , Cs and the equivalent viscous resistance from the friction is 15 25 percent of the critical resistance. By the way, Cs is $0.7 \times 10^{4} \mathrm{~N} \cdot \mathrm{s} / \mathrm{m}$ when there has been equipped the controller. The dynamics performance is simulated at different cases, including that $\varphi$ is $0.025,0.049$ and 0.071 and the constant a is 0 and $5 \mathrm{~mm}$. The controller affects the lateral ride index and acceleration slightly and the most cases are better than without the controller. The compared result of vertical ride index with and without controller is given in fig. 3 and the max vertical acceleration is given in fig.4. Cs is 0 when the controller is not equipped.

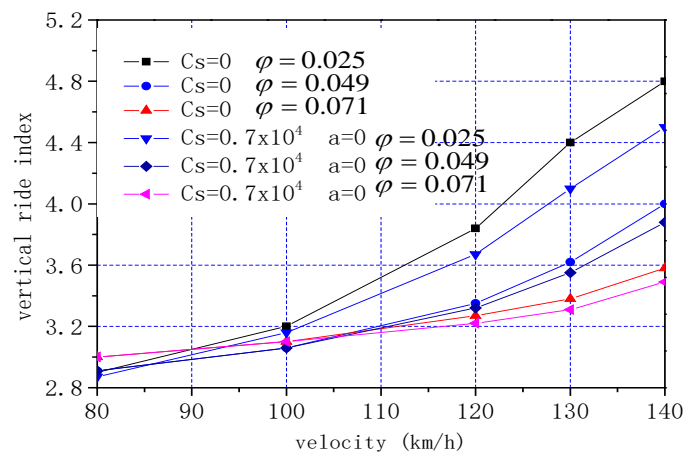

(a) compare with a without controller

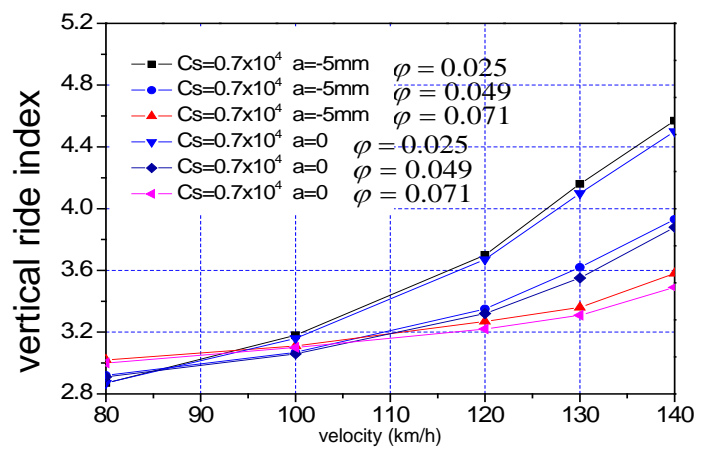

(b) compare different a with controller

Fig.3 compare of the vertical ride index 


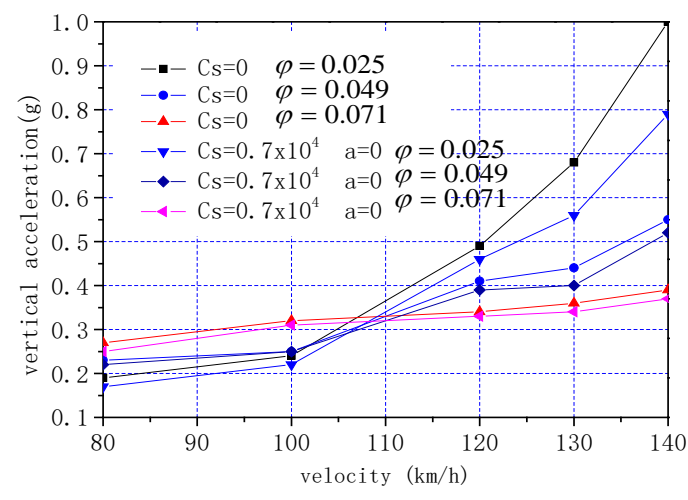

(a) compare with a without controller

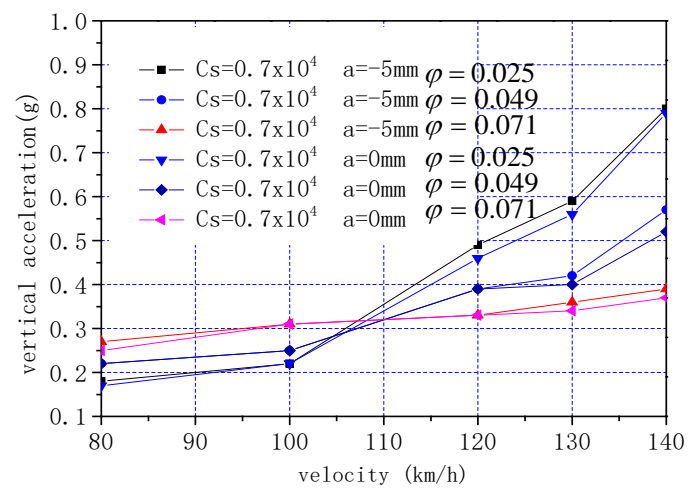

(b) compare different a with controller

Fig. 4 compare of the body vertical acceleration

From fig.3 and fig.4: The vertical ride index and acceleration is improved in largely with the high velocity and the low relative friction coefficient when the controller is equipped, the ride index decreases about 0.3 and the max acceleration lows down about $0.2 \mathrm{~g}$. The vertical ride index and acceleration becomes large without the controller when the velocity is more than $120 \mathrm{~km} / \mathrm{h}$ and the relative friction is less. It is represent the gap when a is not zero. The larger of the absolute ${ }^{a}$, the less of the vertical ride index and acceleration is improved with the controller.

To the loaded performance with the controller, the results has given in table 2,table 3 and table 4. From these table: The affection of the controller is very slightly to ride index of the loaded case and curve passing of the empty case. The wheel unloading ration of the loaded case is increased in large with the controller. This has proved that the controller couldn't take into effect in loaded case. And the simulation has shown that the stable performance is affected very weak with or without the controller.

Table 2 the curve passing performance of empty case $(\mathrm{R}=300 \mathrm{~m}, \mathrm{~V}=70 \mathrm{~km} / \mathrm{h})$

\begin{tabular}{|c|c|c|c|c|}
\hline & \multicolumn{2}{|c|}{$C s=0$} & \multicolumn{2}{c|}{$\begin{array}{c}\text { Cs }=0.7 \times 10^{4} \mathrm{~N} \cdot \mathrm{s} / \mathrm{m} \\
a=0\end{array}$} \\
\hline $\begin{array}{c}\text { Relative friction } \\
\text { coefficient }\end{array}$ & $\varphi=0.025$ & $\varphi=0.071$ & $\varphi=0.025$ & $\varphi=0.071$ \\
\hline $\begin{array}{c}\text { wheel unloading } \\
\text { ratio }\end{array}$ & 0.77 & 0.70 & 0.69 & 0.63 \\
\hline derailment index & 0.43 & 0.42 & 0.42 & 0.42 \\
\hline $\begin{array}{c}\text { Max lateral force } \\
\text { between wheel and } \\
\text { rail (kN) }\end{array}$ & 10.93 & 10.97 & 10.85 & 11.1 \\
\hline
\end{tabular}

Table 3 the curve passing performance of loaded case $(\mathrm{R}=300 \mathrm{~m}, \mathrm{~V}=70 \mathrm{~km} / \mathrm{h})$

\begin{tabular}{|c|c|c|c|c|}
\hline & \multicolumn{2}{|c|}{$C s=0$} & $C s=0.7 \times 10^{4} N \cdot s / m \quad a=0$ \\
\hline $\begin{array}{c}\text { Relative friction } \\
\text { coefficient }\end{array}$ & $\varphi=0.025$ & $\varphi=0.071$ & $\varphi=0.025$ & $\varphi=0.071$ \\
\hline $\begin{array}{c}\text { wheel unloading } \\
\text { ratio }\end{array}$ & 0.44 & 0.38 & 0.78 & 0.7 \\
\hline derailment index & 0.2 & 0.19 & 0.17 & 0.18 \\
\hline $\begin{array}{c}\text { Max lateral force } \\
\text { between wheel and } \\
\text { rail (kN) }\end{array}$ & 21.4 & 21.9 & 21.3 & 21.7 \\
\hline
\end{tabular}


Table 4 ride index of the loaded case compared at $140 \mathrm{~km} / \mathrm{h}$

\begin{tabular}{|c|c|c|c|c|}
\hline & \multicolumn{2}{|c|}{$C s=0$} & \multicolumn{2}{c|}{$C s=0.7 \times 10^{4} N \cdot s / m \quad a=0$} \\
\hline $\begin{array}{c}\text { Relative friction } \\
\text { coefficient }\end{array}$ & $\varphi=0.025$ & $\varphi=0.071$ & $\varphi=0.025$ & $\varphi=0.071$ \\
\hline Vertical ride index & 3.31 & 3.67 & 3.31 & 3.68 \\
\hline $\begin{array}{c}\text { Vertical } \\
\text { acceleration(g) }\end{array}$ & 0.25 & 0.34 & 0.25 & 0.35 \\
\hline
\end{tabular}

\section{Conclusion and Discussion}

The single direction resistance controller has an large affection in the vertical vibration and vertical ride index of the empty case of the mid-cross three-piece bogie freight vehicle, especially when the wedge friction factor is small which result in a small relative damper factor of the vehicle. In empty case, the vertical ride index is distinctly improved with the controller when the speed is high and the relatively friction coefficient is low. To other dynamics performance, such as critical velocity, curve passing, turnout passing, has slightly affection. On passing curve, the wheel unloading ratio becomes high and other dynamics performances are changed weakly in loaded case.

The resistance controller is designed to take into effect in empty case and not to affect the performances of the loaded case. However, there isn't only empty and loaded case. There are many load case between the empty and filled load case to the rail freight vehicle. The center suspension of the bogie is the two class stiffness. All of them have the affection to equipped with the controller. To above case, there need to make progress studying.

With the speed increasing, it is engineer significance that the controller is equipped to take into effect to improve the empty ride index of the rail freight, especially the relative friction coefficient is lowed down simultaneously.

\section{Acknowledgements}

The authors would like to thank the National Nature Science Foundation of China (NSFC). This research work has been substantially supported by NSFC under grant No.61174214.

\section{Reference}

[1] A.H.Wickens. Fundamentals Of Rail Vehicle Dynamics[M]. Netherlands, Sweets \& Zeitlinger Publishers, 2003.

[2] Dukkipati Rao V., Narayana Swamy, S.. Non-linear steady-state curving analysis of some unconventional rail trucks[J]. Mechanism and Machine Theory, 2001, vol.4(36), pp. 507-521

[3] Jones C.J.C., Hardy A.Ee.j., Jones R.R.K. etc. Bogie shrouds and low track-side barriers for the control of railway vehicle rolling noise[J]. Journal of sound and vibration, 1996, Vol.1(193), pp. 427-431

[4] Nielsen J.C.O., Igeland A.. Vertical dynamic interaction between train and track influence of wheel and track imperfections[J]. Journal of sound and vibration, 1995, Vol. 5(187), pp. 825-839

[5] Wang Fu tian. Vehicle system dynamics[M]. Beijing: China rail press,1994

[6] Zhai Wanming. Vehicle-track coupling dynamics [M]. Beijing: China rail press,2001(V2). 